\title{
BMJ Open Quality Improving access to services through a collaborative learning system at East London NHS Foundation Trust
}

\author{
Amar Shah, ${ }^{1}$ Auzewell Chitewe, ${ }^{2}$ Emma Binley, ${ }^{2}$ Forid Alom, ${ }^{2}$ James Innes ${ }^{2}$
}

To cite: Shah A, Chitewe A, Binley $\mathrm{E}$, et al. Improving access to services through a collaborative learning system at East London NHS Foundation Trust.BMJ Open Quality 2018;7:e000337. doi:10.1136/ bmjoq-2018-000337

Received 15 January 2018 Revised 6 June 2018 Accepted 7 July 2018

\section{Check for updates}

(C) Author(s) (or their employer(s)) 2018. Re-use permitted under CC BY-NC. No commercial re-use. See rights and permissions. Published by BMJ.

${ }^{1}$ East London NHS Foundation Trust, London, UK

${ }^{2}$ Quality Improvement Team, East London NHS Foundation Trust, London, UK

Correspondence to Dr Amar Shah, East London NHS Foundation Trust, London E1 8DE, UK; amarshah@nhs.net

\section{ABSTRACT}

Early intervention following initial referral into healthcare services can have a significant impact on the prognosis and outcomes of patients. Long waiting times and nonattendance can have an immediate and enduring negative impact on patients and healthcare service providers. The traditional management options in reducing waiting times have largely revolved around setting performance targets, providing financial incentives or additional resourcing. This large-scale quality improvement project aimed to reduce waiting times from referral to first appointment and non-attendance for a wide range of services providing primary and secondary care mental health and community health services at East London NHS Foundation Trust (ELFT). Fifteen community-based teams across ELFT came together with the shared goal of improving access. These teams were diverse in both nature and geography and included adult community mental health teams, child and adolescent mental health services, secondary care psychological therapy services, memory services, a musculoskeletal physiotherapy service and a sickle cell service. A collaborative learning system was developed to support the teams to come together at regular intervals, share data, test and scale-up ideas through quality improvement and have access to coaching from skilled improvement advisors in the ELFT central quality improvement team. Over the course of the 2-year project, waiting time from referral to first face-to-face appointment reduced from an average of 60.6 days to 46.7 days (a $23 \%$ reduction), non-attendance at first faceto-face appointment reduced from an average of $31.7 \%$ to an average of $20.5 \%$ (a $36 \%$ reduction), while referral volume increased from an average of 1021 per month to an average of 1280 per month (a $25 \%$ increase).

\section{PROBLEM}

East London NHS Foundation Trust (ELFT) is a National Health Service (NHS) provider of predominantly mental health and community health services to a population of 1.5 million people in East London, Bedfordshire and Luton (which are in South East England). The organisation employs approximately 5500 people and has been applying quality improvement across all aspects of its operations for several years. The quality improvement work is led locally by staff, service users and other partners using the systematic method of the Model for Improvement.
The method and associated tools are taught to staff and service users at all levels of the organisation.

The focus on this project was to improve access to community-based services, one of four priority areas of improvement work at ELFT between 2015 and 2017. Quality improvement (QI) at ELFT operates on the ethos that improvement efforts should be identified, initiated and led by teams that have the closest proximity to the quality problem. Fifty-nine projects had started across the organisation looking to improve access to services, spanning efforts as diverse as waiting times, increasing referrals, reducing time to produce reports, reducing non-attendance at appointments, reducing duplication in record keeping, patient transport, carers' group attendance, patient experience, improving internal pathways and so on. Each project was led locally by a project lead from the service.

A recurring theme for the central quality improvement team was that there were pockets of excellent practice and innovation across these teams but no structured way of linking the projects to each other to share their learning. Another recurring theme was that project teams were requesting similar types of improvement expertise to help them with their work. The QI team did not have the capacity to meet the need on a case by case basis. The project teams were invited to come together to think about how best to learn together and identified key competencies and improvement expertise that would be needed to help them make progress. What emerged was a core need to focus on improving access to services by reducing waiting times from referral to first assessment and non-attendance at first appointments. Based on this, the 15 teams who were working explicitly on these issues are their primary aim were brought together in a collaborative learning system. 
A collaborative learning system was then formed, consisting of community teams from adult mental health, older peoples' mental health, child and adolescent mental health and community health services spanning the east London boroughs of Newham, Tower Hamlets, the City and Hackney. Though each team had its own locally determined aim, they set an aim for the collaborative learning system to 'Improving access to services for new patients by increasing uptake, reducing waiting times or reducing DNAs according to locally set targets by March 2017'. This allowed each of the 15 teams across the learning system some flexibility to set their own quantifiable aim, based on their current level of performance and the local context of demand and requirements set by commissioners.

Community-based services at ELFT were experiencing increased waiting times from referral to first assessment and high proportions of non-attendance at first
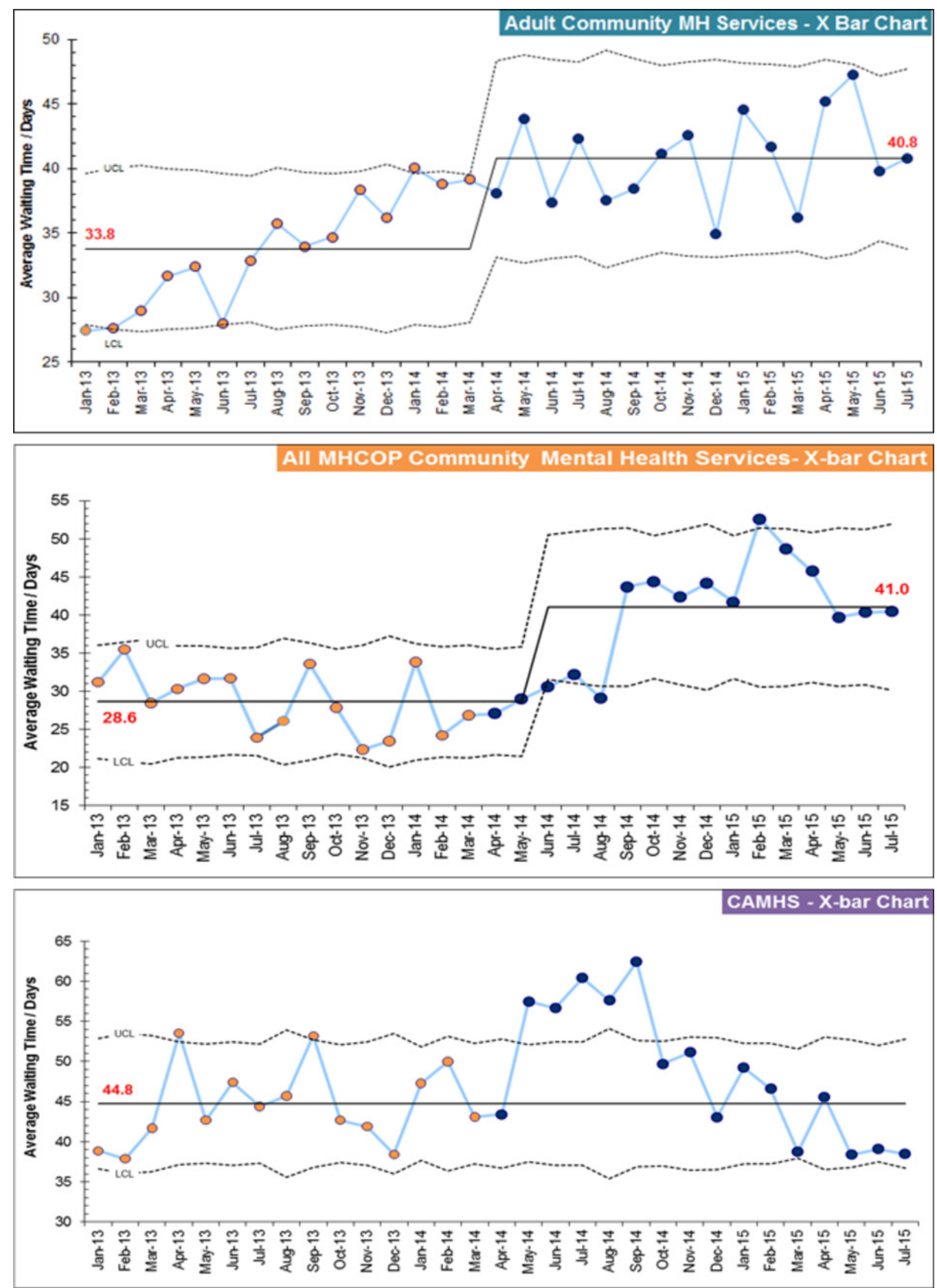

Figure 1 Baseline data on waiting times across community services. CAMHS, child and adolescent mental health services; MHCOP, mental healthcare of older people services. 
appointments (figure 1). Community mental health services had seen a $21 \%$ increase in wait times with an average wait time from referral to first appointment of 41 days. Mental healthcare of older people services were experiencing a $43 \%$ increase in wait times which equated to an average wait time of 41 days. Child and adolescent mental health services had a steady wait time of 44 days. Dissatisfaction with waiting for appointments was a frequent theme in patient experience feedback within community-based services.

\section{BACKGROUND}

Non-attendance is a frequent area of concern for services within the NHS. In relation to mental health services, research evidence suggests that service users do not attend approximately $20 \%$ of psychiatric appointments and of those who miss appointments up to $50 \%$ do not complete treatment or fail to continue to engage with services. ${ }^{1}$ Improving non-attendance is crucial as missing appointments can negatively impact services users' mental health and recovery, missed medication and non-attendance can result in service users disengaging with services and discontinuing the receipt of care. ${ }^{1}$ Research has shown that service users who miss appointments have an increased chance of being admitted to hospital, are more socially impaired and unwell. ${ }^{2}$ In addition, service users' non-attendance at first appointments can be viewed as a burden on staff and financial resources. ${ }^{2}$

There are multiple reasons why service users miss appointments and therefore a complex approach is required to improve this. ${ }^{3}$ A prospective study found that the main reasons for non-attendance at follow-up appointments were: forgetting and being too unwell, whereas the most common reasons for non-attendance at first appointment were: administrative errors, being unhappy and/or not in agreement with the referral, inappropriate referrals and again being too unwell. ${ }^{3}$ Increased wait times and non-attendance are interrelated, for example, research found that attendance to appointments was significantly impacted by the length of time between referral and first appointments. ${ }^{24}$ Therefore, it is crucial that a service understands the potential factors that influence wait times and this understanding can help improve the attendance rates. ${ }^{2}$

Research focused on improving access to services has found a number of interventions that can improve wait times and non-attendance. Examples include reminders and prompts, for example text message reminders ${ }^{5}$ and prompt letters ${ }^{6}$; increasing choice of appointment options; improving communication and explaining the purpose of the service. ${ }^{1}$

\section{MEASUREMENT}

Three measures were chosen and agreed by the collaborative learning system for this work:

- Waiting times: Average time in days from referral being accepted to first face-to-face contact.
- Non-attendance: Proportion of patients who did not attend first face-to-face contact, of the total number of appointments booked (excluding cancellations).

- Referral volume: Total number of referrals received from outside ELFT (external referrals).

Within the learning system, some projects were focused on reducing waiting times as their outcome. These projects would use the waiting times measure as the outcome, with non-attendance and referral volume becoming process measures.

Other projects were focused on reducing non-attendance, so this would become the outcome measure for the project and the other two measures would be process measures.

All projects captured all three measures above, as part of their family of measures for the work, however used them as either outcome or process depending on the aim of the individual project.

At the start of the project, all the teams agreed an operational definition for each of the measures above. There was wide variation in how teams measured waiting times prior to this project, with some counting days waiting from the date of the referral, some starting the count when the referral received the clinic and some starting the count only when the referral was accepted by the team. The process of agreeing the operational definition involved clinical leads from each of the team, and also the local commissioners, to ensure that there was consistency between the data collected for the quality improvement work and data used in reporting for performance management and contractual requirements.

Once the measures and operational definitions were agreed, the data analysts in the central QI team at ELFT extracted the relevant data from the Trust's electronic clinical record system in order to produce automated charts at team, directorate and organisation level on a monthly basis that anyone from the teams could access from the computer. A standard dashboard showing aggregated outcomes and service-specific data was also sent out to all participating teams every month.

\section{DESIGN}

Several quality improvement projects were started by services with aims to reducing wait times or reducing non-attendance to differing local expectations or team ambitions. The central Quality Improvement team then organised these project teams into a collaborative learning system to promote collaboration, accelerate their learning, provide improvement expertise to all teams and senior sponsorship to help overcome barriers at all levels of the organisation.

Collaboration and systems that support collaboration help ensure that service users receive high quality care. ${ }^{7}$ Collaborative learning systems provide teams with an opportunity to share learning and explore ways to overcome challenges. They have been found to increase motivation and stimulate improvement. ${ }^{8} \quad$ Effective 


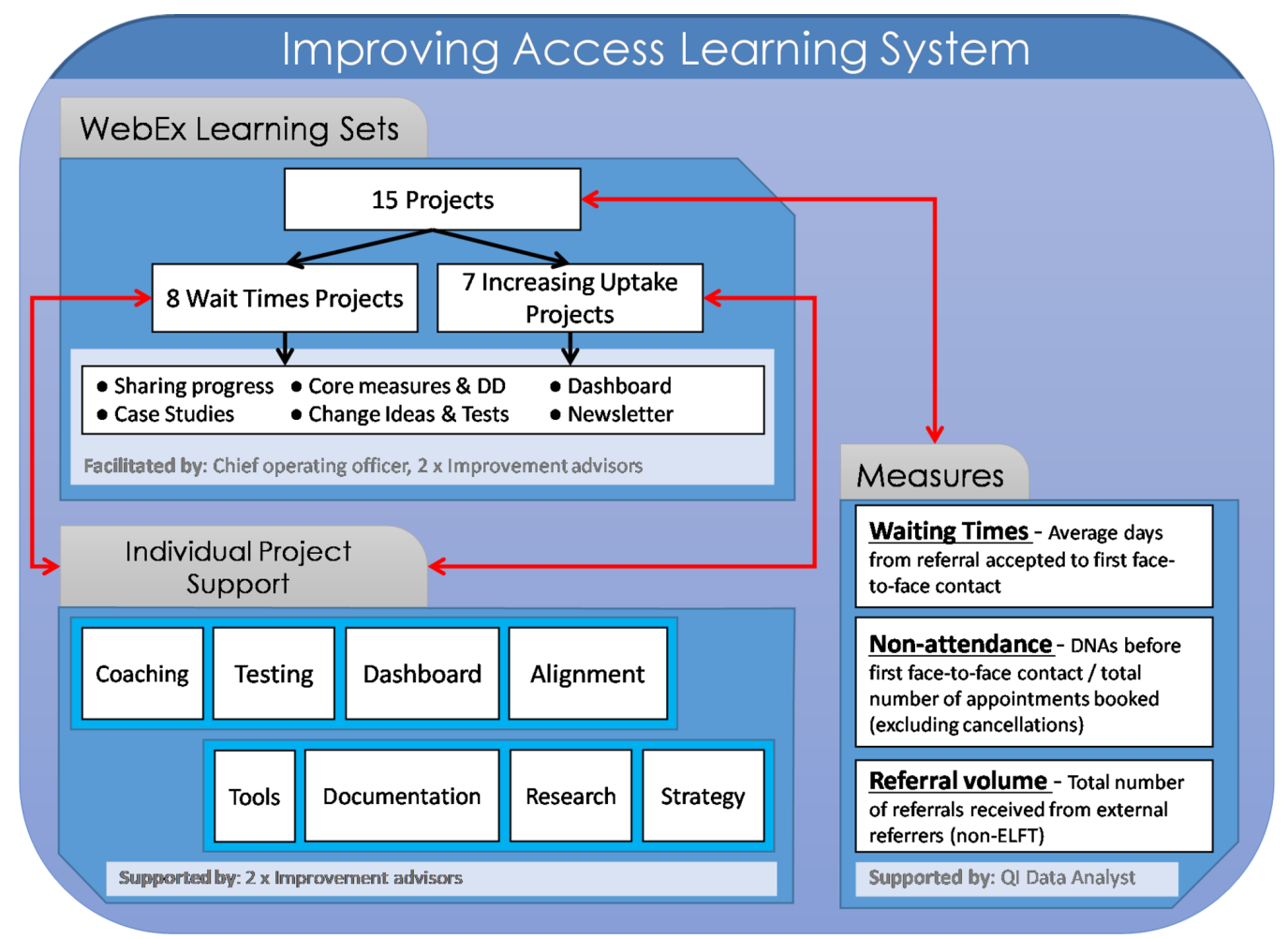

Figure 2 Learning system structure. ELFT, East London NHS Foundation Trust.

collaborative learning systems require multiple components; a shared purpose, sponsorship, support from senior leaders, participants, improvement ideas, preliminary learning and a strategy for capturing the learning from improvements. ${ }^{9}$ It is important that organisations review the current systems and variation prior to the collaborative commencing. ${ }^{6}$ Measurement that is rigorous but not burdensome is key to driving improvements in collaborative learning systems. ${ }^{10}$

The design of the collaborative learning system for this project is shown in figure 2. The collaborative learning system incorporated the following components:

- A shared goal across all the teams.

- A measurement system, with standardised measures that were collected and shared transparently across all the teams.

- A way to learn from each other, with face-to-face learning sets every 6 weeks.

- A support structure, with a project board, an executive sponsor for the whole learning system, local sponsors for each project and improvement advisors coaching each project team.

- A shared theory of change, with a driver diagram created together to visualise how the teams believed they would improve access across their services (figure 3).

As part of the design of the learning system, all the teams contracted with the central quality improvement team and executive sponsor, and agreed the following:

- The Project Team to appoint a project lead.
- The Project Team to meet regularly as a team and invite the improvement advisor from the central QI team.

- At least one member of the team to attend the six weekly collaborative learning sets.

- Copy the central QI Team into updates to the team's sponsor and coach.

- Save project documentation into a shared network folder, so others could also access.

- Use the three core measures for the collaborative as a minimum (non-attendance, Waiting Times, Referral volume).

- A dedicated improvement advisor from the central QI Team would be assigned to support the project team with all areas of their project.

\section{STRATEGY}

Within the collaborative learning system for this strategic improvement priority, multiple change ideas were tested by the teams involved, with close support from the central QI team and with an executive sponsor retaining oversight. As change ideas are shown to work in a single team, the collaborative learning system allowed rapid testing in another team with different conditions, to assess suitability for scaling up. The learning system also allowed more tactical testing of change ideas, so that there was less replication of ideas, and faster learning.

The standard approach to quality improvement work at ELFT includes five stages:

- Identifying the quality issue (including forming the team and engaging all stakeholders). 

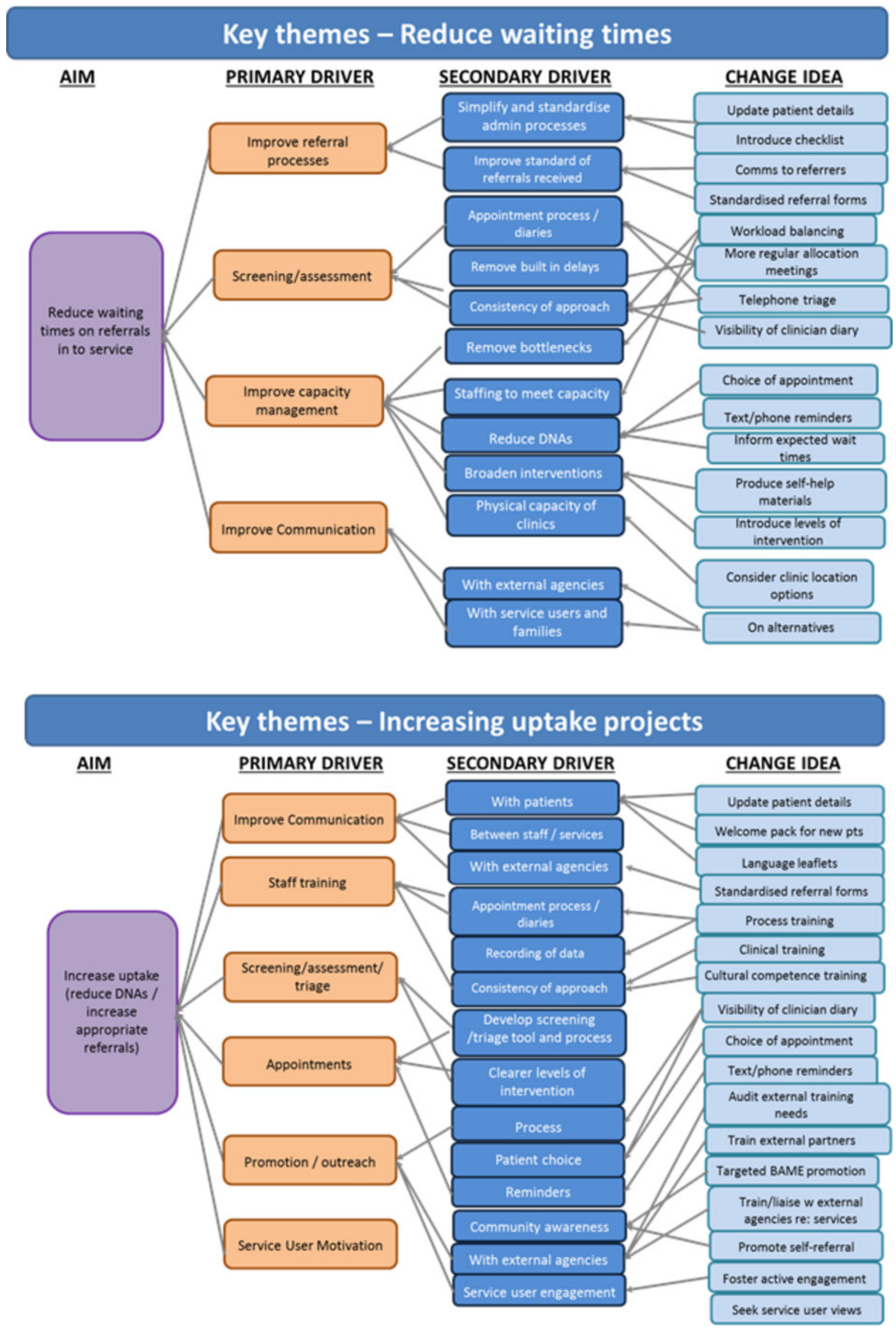

Figure 3 Driver diagram representing the theory of change for reducing waiting times and increasing uptake. 
- Understanding the problem.

- Developing a strategy and change ideas.

- Testing.

- Implementing and sustaining the gains.

All the teams within this collaborative learning system undertook the same sequence. Each team was represented at each learning session, with at least one person from the team attending. The learning sessions were designed and facilitated by an improvement advisor, and the executive sponsor chaired the session.

At the start of this work, the teams came together to form two shared theories of change: one for reducing waiting times for referrals into their service, and one for increasing uptake (reducing non-attendance at appointments). These are both shown in figure 3 .

The teams tested multiple change ideas across the duration of the 2-year project. As this paper describes the work across the whole collaborative learning system, the individual PDSA tests of change carried out by each time will not be described. However, the teams came together every 6 weeks (either face-to-face or virtually) to discuss the tests being run by all the teams and to share their knowledge and degree of belief regarding the change ideas. 'Degree of belief' is a key concept in quality improvement and describes the ability to predict and evidence the effect of a change idea on the outcome of interest within a given environment. As teams test an idea and learn the effect that it has under differing conditions, the team's degree of belief about the idea's ability to impact on the outcome of interest may either increase (if the idea seems to work) or decrease (if the idea does not work).

As teams began testing ideas, it was decided to enhance learning across teams and build momentum for the work through an electronic newsletter, created by the central QI team, in-between the learning sets. Figure 4 shows a full list of the change ideas tested across the teams, grouping the ideas by the relevant change concept.

\section{RESULTS}

Figure 5 shows the data for the three core measures across the whole collaborative learning system. This shows that over the course of the 2-year project, waiting time from referral to first face-to-face appointment reduced from an average of 60.6 days to 46.7 days (a $23 \%$ reduction), non-attendance at first face-to-face appointment reduced from an average of $31.7 \%$ to an average of $20.5 \%$ (a $36 \%$ reduction), while referral volume increased from

\begin{tabular}{|c|c|c|}
\hline Change Concept & Change Idea & Teams Testing \\
\hline $\begin{array}{l}17 \text { - Use automation } \\
59 \text { - Use reminders }\end{array}$ & $\begin{array}{l}\text { iPLATO text messaging system (automated system). } \\
\text { Task to gather views on how to achieve consistency } \\
\text { in processes }\end{array}$ & $\begin{array}{l}\text { MSK Physio; Newham EPCL; } \\
\text { Specialist Health Visiting; NH } \\
\text { Psychological Therapies; TH CAMHS; } \\
\text { TH Psychological Therapies }\end{array}$ \\
\hline 59 - Use reminders & $\begin{array}{l}\text { EE text message reminders (manual Microsoft } \\
\text { Outlook system). }\end{array}$ & $\begin{array}{l}\text { Community Sexual Health and } \\
\text { Reproductive health; } \mathrm{CH} \text { Wait Times }\end{array}$ \\
\hline $\begin{array}{l}39-\text { Coach customers to use } \\
\text { products/service }\end{array}$ & $\begin{array}{l}\text { Assessment leaflet to provide information about the } \\
\text { process of assessment, therapy choice etc }\end{array}$ & NH Psychological Therapies \\
\hline 51 - Standardization & $\begin{array}{l}\text { Referral form that was developed and tested by the } \\
\text { NH Psychological Therapies wait times project }\end{array}$ & $\begin{array}{l}\text { TH Psychological Therapies, } \mathrm{CH} \\
\text { Psychological Therapies }\end{array}$ \\
\hline $\begin{array}{l}34-\text { Focus on the core process and } \\
\text { purpose } \\
68-\text { Reduce the number of components }\end{array}$ & $\begin{array}{l}\text { Stopping groups for patients awaiting individual } \\
\text { psychotherapy }\end{array}$ & CH Psychological Therapies \\
\hline $\begin{array}{l}21 \text { - Use multiple processing units } \\
55 \text { - Develop contingency plans }\end{array}$ & Emergency clinic slot & Specialist health visiting \\
\hline 41 - Use a coordinator & $\begin{array}{l}\text { Referrals coordinator screens and either accepts or } \\
\text { sign-posts new referrals }\end{array}$ & CH Psychological Therapies \\
\hline 14 - Minimize hand-offs & Post appointment letters directly from team & CH Wait Times \\
\hline
\end{tabular}

Figure 4 List of change ideas tested within the learning system, linked to the relevant change concept. CAMHS, child and adolescent mental health services; $\mathrm{CH}$, City \& Hackney; EE is the text message network; EPCL, extended primary care liaison; LCL, lower control limit; NH, Newham; MSK, Muskuloskeletal; PDSA, Plan-Do-Study-Act; QI, quality improvement; TH, Tower Hamlets; UCL, upper control limit. 

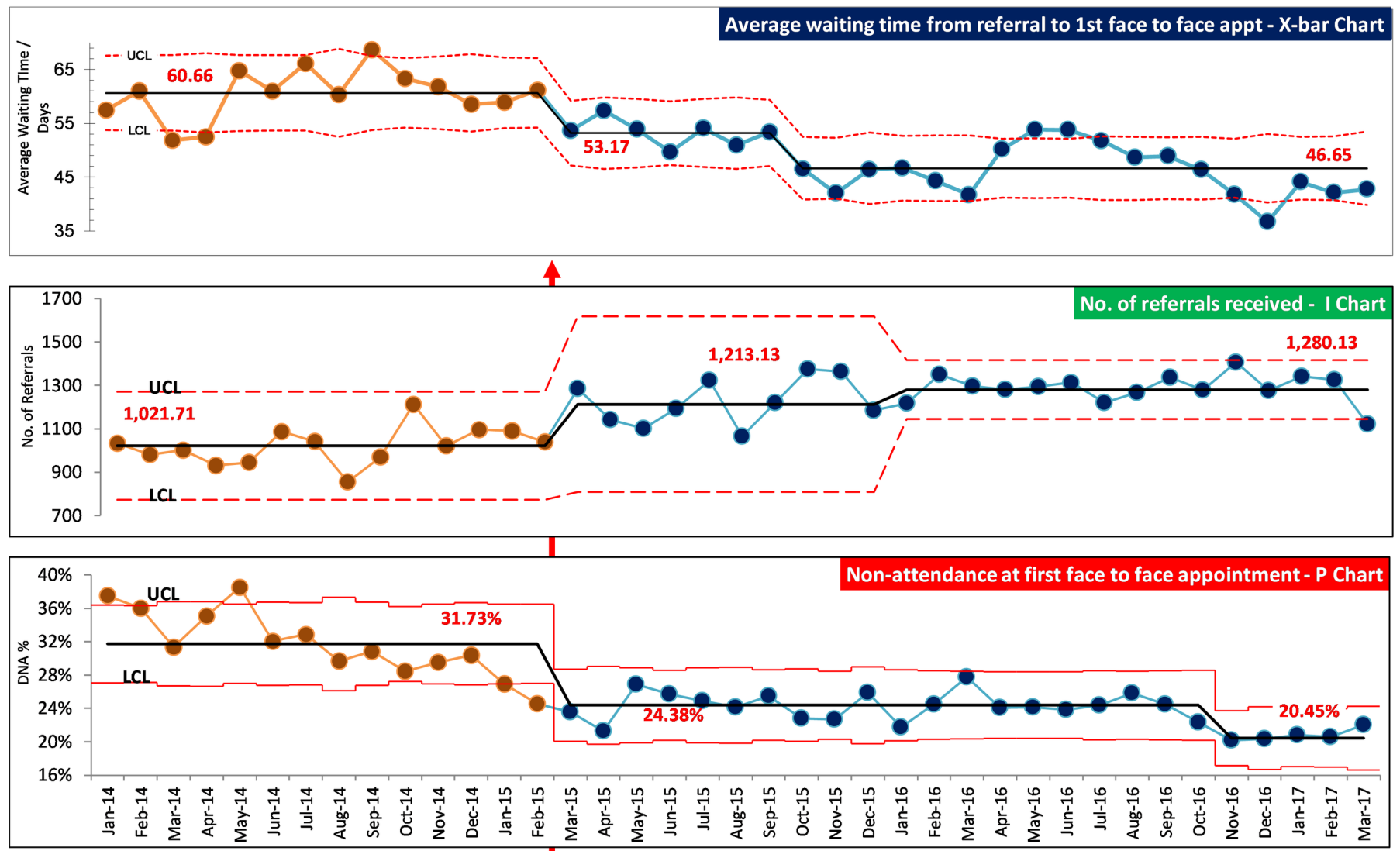

|

Figure 5 Outcome measures for the learning system.

an average of 1021 per month to an average of 1280 per month (a 25\% increase).

The change idea related to reducing non-attendance at appointments which the teams developed the greatest degree of belief in was text message reminders. Of the change ideas tested to reduce waiting times from referral to first face-to-face contact, the change ideas which the teams developed greatest degree of belief in were the use of telephone triage, making self-help materials available, using checklists and increasing the number of allocation meetings to allocate referrals to the suitable clinical pathway.

\section{LESSONS AND LIMITATIONS}

This paper has presented the work done across a large collaborative learning system for a strategic improvement initiative at ELFT. We have therefore not had the opportunity to discuss the work happening within each of the teams taking part in this work and have focused instead on the design of the collaborative learning system that helped accelerate learning across the teams and brought shared purpose across diverse community teams. The paper therefore does not provide us with the opportunity to explore the relative contribution of the individual change ideas and change concepts to the outcome of interest, as we have not presented data at individual project level. This discussion, however, was one that was active throughout the 2 years of the work within the learning sets as the teams were eager to identify ideas being tested by other teams that had been shown to work and which might have application to their own context. An alternative, which the team did not entertain at the time, would have been to run a quasi-experimental design, such as planned experimentation, in order to test multiple changes across a number of teams. This would have required some considerable planning and expertise, which was not readily available at ELFT in 2015 when this project commenced, but which was later applied to another large piece of improvement work a year later. Had this design been chosen, we would have had the opportunity to understand better the interaction between different change ideas on the outcome of interest.

This project included a variety of teams working in different geographies and with different types of patient, 
from children's teams to memory clinics. Our belief was that there would be sufficient generalisability in change concepts and change ideas across these teams as long as they were working on the first part of the pathway into a service. This was demonstrated to be the case, as change ideas tested in one service and shown to work, were also shown to work across the other settings.

One challenge was to capture the learning at teamlevel. At the time of this work, we were reliant on teams recording their PDSA tests of change using paper or Word documentation. This was less than reliable, and we were largely dependent on the improvement advisors supporting the teams to log the changes being tested and the detail of the theory, prediction and data for each test of change. As a result of this learning, the team at ELFT have now developed an online platform with a third-party software developer to make it much easier for teams to $\log$ their PDSA's, create driver diagrams, input and view their data as control charts.

A significant challenge with this work was to standardise the operational definitions across the system before undertaking the project. With such diverse teams in the learning system, all needed to be recording the three measures in the same way, in order to be able to learn effectively from each other. This was a major challenge, as the teams had developed very different ways of working and measuring over the years, were managed through quite separate directorates and professional leads, and this also meant having to liaise with multiple sets of local commissioners in order to agree a common operational definition. This took some time to finalise, but without this agreement, it would have been impossible for the teams to learn together.

The pathway into a service can become highly sensitive and political. There was a high degree of interest in this work from commissioners, as waiting times and non-attendance became areas of dissatisfaction. It was an ongoing challenge to protect the integrity of the quality improvement approach, allowing teams to identify their own ideas for improvement and test these systematically and managing to hold off the traditional performance management approach of setting targets, micromanaging and mandating actions. The key factor in achieving this was the active involvement of an executive sponsor for the collaborative learning system, and the fact that this was the chief operating officer who also had regular liaison with the local commissioners.

A risk of working on the first part of a pathway into services, as with this large quality improvement project, is that performance may deteriorate further into the pathway. All community teams within this collaborative learning system were monitoring contractual performance indicators through this piece of improvement work, and no deterioration was noted. However, this initial 2year piece of work on improving access into services has now evolved into a larger improvement project on improving access and flow through the entire pathway, as services have recognised that optimising flow in a sustainable way requires managing the whole pathway, including transition out of the service.

\section{CONCLUSION}

This project has shown the value of using a collaborative learning system and quality improvement in order to tackle a complex quality issue. For many years at ELFT, there was widespread recognition that waiting times were too long but a reluctance to tackle the issue or even talk about it openly. The fear was that the only solution to this problem was more resource, which was not easily available.

The introduction of quality improvement at ELFT in 2014 has challenged this assumption and shown across many areas of the organisation that it is possible to achieve something truly remarkable, through solutions generated within the team at very little or no cost. This project managed to achieve remarkable reductions in waiting times from referral to first appointment, and non-attendance at first appointment, despite no additional resource. The only extra resource was the quality improvement support provided to the teams, and the expense of bringing teams together in order to learn from each other.

It is worth keeping in mind that all of these teams had access to quality improvement training through the years of this project, so many of the project team members and leads will have undertaken a 6-month programme of learning to equip themselves with a deep level of knowledge about improvement science. This is critical to allow teams to use a systematic method to tackle a complex problem.

The collaborative learning system, which commenced in 2015, brought together a diverse range of teams. Some of these teams were very similar in nature, were managed through a common operational management structure and were working on similar topics-yet were not sharing and learning from each other prior to the introduction of this collaborative learning system. There was real power in bringing together a diverse set of teams at regular intervals, who were working with a shared purpose yet in very different contexts, in order to facilitate faster learning and scale-up of successful ideas. The active involvement and oversight of an executive sponsor was key to these teams feeling that their work mattered to the leadership and to see how their work aligned to the Trust's organisational priorities. The skilled improvement advisors that supported the teams closely were key in ensuring fidelity to the quality improvement method of iterative testing and using data over time.

Reducing waiting times and non-attendance has helped these teams become more efficient, as there is less time lost in clinics when service users fail to attend. Seeing patients faster helps the teams support people quicker when in need and prevents conditions worsening. Importantly, the teams themselves have recognised that they have control over the system they work in and can achieve 
a new level of performance, simply by understanding their processes, involving people deeply in identifying new ideas and testing these systematically.

Although the collaborative learning system ended in April 2017, all these teams have access to their data through an online portal in order to enable them to sustain their gains and keep an eye on maintaining the new level of performance. Many teams have moved on from this work to now looking to improve flow across their entire pathway, rather than just focusing on the front-end of the pathway. At ELFT, the next strategic improvement project was to focus on improving access and flow across whole pathways, and since this project closed in April 2017, the central quality improvement team has been designing and supporting a large number of teams (some new, some existing) to understand flow through entire pathways and apply a similar quality improvement approach with a collaborative learning system to achieve a step-change in performance.

Acknowledgements The authors would like to acknowledge all the staff and service users across all the teams within this work, who have contributed time, energy and ideas into improving access across our community services.

Contributors $\mathrm{AC}$ and $\mathrm{EB}$ designed the project and supported teams through the work. FA supported the measurement, data collection and analysis. JI and AS provided supervision and senior improvement expertise in the design and through the project work. AC and AS led on the submission of the paper.

Funding The authors have not declared a specific grant for this research from any funding agency in the public, commercial or not-for-profit sectors.

Competing interests None declared.

Patient consent Not required.
Provenance and peer review Not commissioned; externally peer reviewed.

Open access This is an open access article distributed in accordance with the Creative Commons Attribution Non Commercial (CC BY-NC 4.0) license, which permits others to distribute, remix, adapt, build upon this work non-commercially, and license their derivative works on different terms, provided the original work is properly cited, appropriate credit is given, any changes made indicated, and the use is non-commercial. See: http://creativecommons.org/licenses/by-nc/4.0/.

\section{REFERENCES}

1. Mitchell AJ, Selmes T. Why don't patients attend their appointments? Maintaining engagement with psychiatric services. Advances in Psychiatric Treatment 2007;13:423-34.

2. Grunebaum M, Luber P, Callahan M, et al. Predictors of missed appointments for psychiatric consultations in a primary care clinic. Psychiatr Serv 1996;47:848-52.

3. Gallucci G, Swartz W, Hackerman F. Impact of the wait for an initial appointment on the rate of kept appointments at a mental health center. Psychiatr Serv 2005;56:344-6.

4. Killaspy H, Banerjee S, King M, et al. Prospective controlled study of psychiatric out-patient non-attendance. British Journal of Psychiatry 2000;176:160-5

5. Filippidou M, Lingwood S, Mirza I. Reducing non-attendance rates in a community mental health team. BMJ Qual Improv Rep 2014;3:u202228.w1114-4.

6. Jayaram M, Rattehalli RD, Kader I. Prompt letters to reduce nonattendance: applying evidence based practice. , 2008:8, 1-8.

7. Ham C, Berwick D. Organising care at the NHS front line. Who is responsible? London: The Kings Fund, 2017. https://www.kingsfund. org.uk/sites/files/kf/field/field_publication_file/Organising_care_NHS_ front_line_Kings_Fund_May_2017.pdf

8. ØVretveit J, Bate P, Cleary P, et al. Quality collaboratives: lessons from research. Qual Saf Health Care 2002;11:345-51.

9. Wilson T, Berwick DM, Cleary PD. What do collaborative improvement projects do? Experience from seven countries. Jt Comm J Qual Saf 2003;29:85-93.

10. Kilo CM. A framework for collaborative improvement: lessons from the Institute for Healthcare Improvement's Breakthrough Series. Qual Manag Health Care 1998;6:1-14. 